\title{
Evaluation of Respiratory Muscle Strength in the Acute Phase of Stroke: The Role of Aging and Anthropometric Variables
}

\author{
Gustavo José Luvizutto, PhD, ${ }^{*}$ Maria Regina Lopes dos Santos, PT, ${ }^{*}$ \\ Lorena Cristina Alvarez Sartor, $\mathrm{PT}^{*}$ Josiela Cristina da Silva Rodrigues, $\mathrm{PT},{ }^{*}$ \\ Rafael Dalle Molle da Costa, ${ }^{2 T},{ }^{*}$ Gabriel Pereira Braga, PhD, + \\ Letícia Cláudia de Oliveira Antunes, $\mathrm{PhD},{ }^{*}$ Juli Thomaz Souza, MsC, $\neq$ \\ Hélio Rubens de Carvalho Nunes, Msc, $\ddagger$ Silméia Garcia Zanati Bazan, PhD, $\ddagger$ and \\ Rodrigo Bazan, PhD†
}

\begin{abstract}
Background: During hospitalization, stroke patients are bedridden due to neurologic impairment, leading to loss of muscle mass, weakness, and functional limitation. There have been few studies examining respiratory muscle strength (RMS) in the acute phase of stroke. Objective: This study aimed to evaluate the RMS of patients with acute stroke compared with predicted values and to relate this to anthropometric variables, risk factors, and neurologic severity. Methods: This is a cross-sectional study in the acute phase of stroke. After admission, RMS was evaluated by maximal inspiratory pressure (MIP) and maximal expiratory pressure (MEP); anthropometric data were collected; and neurologic severity was evaluated by the National Institutes of Health Stroke Scale. The analysis of MIP and MEP with predicted values was performed by chi-square test, and the relationship between anthropometric variables, risk factors, and neurologic severity was determined through multiple linear regression followed by residue analysis by the Shapiro-Wilk test; $P<.05$ was considered statistically significant. Results: In the 32 patients studied, MIP and MEP were reduced when compared with the predicted values. MIP declined significantly by 4.39 points for each $1 \mathrm{~kg} / \mathrm{m}^{2}$ increase in body mass index (BMI), and MEP declined significantly by an average of 3.89 points for each $1 \mathrm{~kg} /$ $\mathrm{m}^{2}$ increase in BMI. There was no statistically significant relationship between MIP or MEP and risk factors, and between MIP or MIP and neurologic severity in acute phase of stroke. Conclusion: There is a reduction of RMS in the acute phase
\end{abstract}

\footnotetext{
From the *Department of Applied Physical Therapy - Institute of Health Sciences, Federal University of Triângulo Mineiro (UFTM), Uberaba, MG, Brazil; +Department of Neurology, Psychology and Psychiatry, Botucatu Medical School (UNESP), Botucatu, SP, Brazil; and ‡Department of Internal Medicine, Botucatu Medical School (UNESP), Botucatu, SP, Brazil.

Received February 4, 2017; revision received April 29, 2017; accepted May 12, 2017.

Author contributions: M.R.L.S., J.C.R.S., L.C.A.S., and S.G.Z.B. were responsible for project inception. J.C.S.R., M.R.L.S., G.J.L., R.D.M.C., L.C.O.A., R.B., and S.G.Z.B. were involved in study design, protocol preparation, drafting the manuscript, and acquisition of funding. H.R.C.N. conceived the statistical analyses and sample size. M.R.L.S. has been involved in data collection. All authors have reviewed and approved the final manuscript.

Ethics approval and consent to participate: This study was approved by a Committee for Ethics in Research involving human subjects from Botucatu Medical School. On inclusion, all subjects were asked for their written informed consent to participate in accordance with the Declaration of Helsinki II.

Address correspondence to Gustavo José Luvizutto, PhD, Departamento de Fisioterapia Aplicada, Universidade Federal do Triângulo Mineiro, Casa Terra. Rua Capitão Domingos, 309. Abadia, Uberaba, MG, Brazil. E-mail: gluvizutto@gmail.com.

$1052-3057 / \$$ - see front matter

(C) 2017 National Stroke Association. Published by Elsevier Inc. All rights reserved.

http://dx.doi.org/10.1016/j.jstrokecerebrovasdis.2017.05.014
} 
of stroke, and RMS was lower in individuals with increased age and BMI. Key

Words: Stroke-respiratory muscle strength-MIP-MEP—obesity—aging.

(C) 2017 National Stroke Association. Published by Elsevier Inc. All rights reserved.

\section{Introduction}

Stroke affects approximately 16.9 million people worldwide, generating about 100,000 people with functional disability per year. ${ }^{1}$ Stroke is the main cause of mortality and chronic disability in adults in Latin America and Brazil, with around 200,000 cases annually. ${ }^{2-4}$

Stroke is defined as neuronal death due to prolonged ischemia, which is caused by obstruction to cerebral blood flow or intracranial hemorrhage. ${ }^{5,6}$ About $90 \%$ of patients present hemiparesis, with decreased strength and motor control after stroke, compromising daily life activities, mobility, and locomotion. ${ }^{7,8}$

During hospitalization, stroke patients become bedridden due to neurologic impairment, leading to loss of muscle mass, weakness, and functional limitation. ${ }^{9}$ The main complications during hospitalization due to immobility are reduction of chest expansion and respiratory complications, with pneumonia being the most common in this population. ${ }^{10}$

Respiratory complications may also occur due to changes in respiratory patterns, as well as from weakness of respiratory muscles. Respiratory muscle strength (RMS) is one of the most important factors in maintaining intact lung function. ${ }^{11}$ Weakened muscles result in decreased diaphragmatic movement and chest expansion, thus increasing mechanical resistance to respiration, and decreased ventilation and cough effectiveness, thus leading to difficulty in eliminating secretions, which significantly increases the risk of lung infections. ${ }^{12}$ In detailed physiological studies of respiratory muscle function, it was found that parameters of RMS (maximum inspiratory and expiratory mouth pressures, sniff pressure) in stroke subjects were reduced by one third to one half, and can be of importance in achieving physical capacity a posteriori and the ability to perform daily life activities in the long term. . $^{13,14}$

There have been few studies that examine RMS in the acute phase of stroke, and the present study has as an innovation the description and the relationship of sociodemographic factors and their impact on RMS in the acute phase of stroke, so that health professionals are attentive in the conduct of clinical care and to the patient with potential risk of respiratory complications. We hypothesized that low values of inspiratory and expiratory pressure decrease the efficiency of ventilatory mechanics, especially in individuals with aging and higher comorbidities in acute phase of stroke; therefore, the aim of this study was to evaluate the RMS of patients with acute stroke compared with the predicted values and to relate this to anthropometric variables and severity of the neurologic condition.

\section{Methods}

\section{Study Design, Setting, and Participants}

This is a cross-sectional study of patients admitted to the stroke unit of the Botucatu Medical School from July until December 2016. We evaluated individuals with a diagnosis of ischemic stroke confirmed by neuroimaging (computed tomography or magnetic resonance), aged over 18 years, and who scored 0 in item 1a of the National Institutes of Health Stroke Scale (NIHSS). Patients with hemorrhagic stroke, previous complaints of dysphagia, prior stroke with a score of more than 2 on the modified Rankin scale, pre-existing dementia, clinical instability, comatose state, acute and chronic pulmonary diseases, and other neurologic diseases were excluded. After signing the informed consent, RMS and both demographic and anthropometric data, in addition to the NIHSS scale, were evaluated in the stroke unit.

\section{Variables}

\section{Exposures}

The independent variable RMS was evaluated using the Comercial Médica (São Paulo, Brazil) manovacuometer, with maximal inspiratory pressure (MIP) and maximal expiratory pressure (MEP) being evaluated until 48 hours after admission.

\section{Measurements}

(A) Maximum inspiratory pressure (MIP): the patient was positioned at $45^{\circ}$ on the bed and was requested to perform maximum expiration up to the residual volume level. Subsequently, maximal inspiratory effort was requested, and held for about 1 second. The reading of the measurement value was checked directly on the manovacuometer display. The maneuvers were repeated 3 times, at intervals of about 1 minute, with the highest MIP value used in the analysis.

(B) Maximum expiratory pressure (MEP): the patient was positioned at $45^{\circ}$ on the bed and was requested to perform maximum inspiratory effort until total lung capacity was reached. A maximal expiratory effort was then requested, and maintained for about 1 second. The reading of the measurement value was checked directly on the manovacuometer display. The maneuvers were repeat- 
ed 3 times, at intervals of about 1 minute, with the highest MEP value used in the analysis.

The test was performed by a trained physiotherapist with more than 5 years of clinical experience in RMS testing. During the maneuvers (MIP and MEP), the patient used a mouthpiece and a nose clip. During the force measurement maneuver, the manovacuometer was occluded manually. In the mouthpiece was a minimal orifice to allow inspiratory flow, in order to avoid closure of the glottis during the maneuver. ${ }^{15,16}$

\section{Confounding Factors}

The following clinical variables were evaluated as potential confounders:

(A) Hemodynamic variables: respiratory rate, systolic and diastolic blood pressure, heart rate, peripheral oxygen saturation, blood glucose monitoring, and temperature.

(B) Anthropometric variables: body weight $(\mathrm{kg})$ was measured by means of a digital scale in patients who could perform an orthostatic posture or by an electronic balance fixed to a crane for bedridden patients. The height (m) was measured by means of a stadiometer fixed to the wall for standing patients. When it was not possible to gauge weight and height, weight and height were estimated by the nutritionist responsible, through formulas taking into consideration age, race, arm circumference, and knee height. After measuring weight and height, the body mass index (BMI) was calculated using the formula: weight $(\mathrm{kg}) /$ height $(\mathrm{m})^{2}$.

(C) Collection of risk factors through the patient admission procedure: hypertension, smoking, obesity, alcoholism, Chagas disease, congestive heart failure, coronary artery disease, diabetes, dyslipidemia, depression, prior stroke or transient ischemic attack, and prior acute myocardial infarction.

(D) Neurologic severity: evaluated through the NIHSS composed of 11 neurologic evaluation items; the higher the score, the worse the neurologic status. ${ }^{17}$

\section{Sample Size}

Because we are using a sample representative of the target population, our sampling is considered to be intentional and nonprobabilistic. We needed a minimum of 60 subjects to obtain a maximum sampling error of $7.5 \%$ and a confidence level of $95 \%$.

\section{Statistical Methods}

The MIP and MEP values were described in the mean and standard deviation and the comparison with the predictive values was obtained using the Student's $t$-test. The predicted values of MIP and MEP for the study population were obtained through the equations proposed by Neder et al. ${ }^{18}$ The analysis of the relationship between
MIP and MEP according to the clinical variables was performed through multiple linear regression followed by residue analysis by the Shapiro-Wilk test. Data were analyzed using SPSS version 22 (IBM SPSS Statistics for Windows, IBM Corp., Armonk, NY), and considered statistically significant at $P<.05$.

\section{Results}

Thirty-two patients were studied: $43.7 \%$ were men, with a median age of 62.5 years, $87.5 \%$ were Caucasian. The most commonly observed risk factors were hypertension (81.2\%), smoking (53.1\%), and diabetes (37.5\%). The TOAST (Trial of Org 10172 in Acute Stroke Treatment) classification with the most frequency (34.3\%) was lacunar stroke, and $46.9 \%$ of the patients presented strokes of unknown cause. The previous modified Rankin scale was 0 in $71.9 \%$ of patients, and the NIHSS median score for hospital admission was 3. Of the patients evaluated, $18.7 \%$ were thrombolytic and 53.1\% underwent physiotherapy during hospitalization (Table 1). Regarding the hemodynamic variables, the values obtained were within the normal range, which made it possible to perform the manovacuometry safely and without intercurrences (Table 2).

The median of MIP obtained was $62.4 \pm 35.3 \mathrm{cmH}_{2} \mathrm{O}$ in total $\left(85 \pm 36.2 \mathrm{cmH}_{2} \mathrm{O}\right.$ in men and $46.9 \pm 25.4 \mathrm{cmH}_{2} \mathrm{O}$ in women), whereas for MEP, it was $65.2 \pm 35.9 \mathrm{cmH}_{2} \mathrm{O}$ in total $\left(82.4 \pm 28.9 \mathrm{cmH}_{2} \mathrm{O}\right.$ in men and $51.2 \pm 28.8 \mathrm{cmH}_{2} \mathrm{O}$ in women). When respiratory pressures were compared with the predicted value, a significant reduction in MIP was observed in the total sample $(P=.001): P=005$ in men and $P=.001$ in women. When compared with the predicted values, a reduction in MEP was observed in the total sample $(P=.001): P=.001$ in men and $P=.001$ in women (Table 3).

MIP dropped significantly by 4.39 points for each $1 \mathrm{~kg} /$ $\mathrm{m}^{2}$ increase in BMI. In this analysis, age was considered as confounding. There was no statistically significant relationship between MIP and other risk factors, severity of the neurologic condition in the acute phase of stroke, and treatment received (Table 4).

MEP declined significantly by an average of 3.89 points per $1 \mathrm{~kg} / \mathrm{m}^{2}$ increase in BMI. There was no statistically significant relationship between MEP with other risk factors, severity of the neurologic condition in the acute phase of stroke, and treatment received (Table 5).

\section{Discussion}

The respiratory pressures presented a reduction in the acute phase of stroke when compared with the predicted value for each sex and corrected for age. In the acute phase of stroke, inhibition of the cortical activity contributes to the reduction of motor control, hemiplegia, and weakness of the trunk muscles, mainly of the diaphragm and abdominal muscle. ${ }^{19-22}$ The abdominal 
Table 1. Demographic and clinical variables of the patients studied

\begin{tabular}{|c|c|c|}
\hline Variable & $\mathrm{n}$ & $\%$ \\
\hline \multicolumn{3}{|l|}{ Demographic } \\
\hline Sex (male) & 14 & 43.7 \\
\hline Age $(y)^{*}$ & $62.5(31-89)$ & \\
\hline \multicolumn{3}{|l|}{ Race } \\
\hline Caucasian & 28 & 87.5 \\
\hline Non-Caucasian & 4 & 12.5 \\
\hline \multicolumn{3}{|l|}{ Risk factors } \\
\hline Hypertension & 26 & 81.2 \\
\hline Smoking & 17 & 53.1 \\
\hline Obesity & 5 & 15.6 \\
\hline Diabetes & 12 & 37.5 \\
\hline Alcoholism & 10 & 31.2 \\
\hline Dyslipidemia & 8 & 25 \\
\hline Prior stroke & 8 & 25 \\
\hline $\mathrm{CHF}$ & 0 & 0 \\
\hline Prior AMI & 2 & 6.2 \\
\hline CAD & 0 & 0 \\
\hline Depression & 2 & 6.2 \\
\hline \multicolumn{3}{|l|}{ Bamford } \\
\hline LACS & 11 & 34.3 \\
\hline PACS & 9 & 28.1 \\
\hline TACS & 3 & 9.4 \\
\hline POCS & 9 & 28.1 \\
\hline \multicolumn{3}{|l|}{ TOAST } \\
\hline Large-artery atherosclerosis & 3 & 9.4 \\
\hline Cardioembolism & 6 & 18.7 \\
\hline Small-vessel occlusion & 3 & 9.4 \\
\hline Other determined etiology & 5 & 15.6 \\
\hline Undetermined etiology & 15 & 46.9 \\
\hline \multicolumn{3}{|l|}{ Prior mRS } \\
\hline 0 & 23 & 71.9 \\
\hline 1 & 5 & 15.6 \\
\hline 2 & 4 & 12.5 \\
\hline NIHSS at admission* & $3(0-16)$ & \\
\hline Thrombolysis & 6 & 18.7 \\
\hline Physioterapy & 17 & 53.1 \\
\hline
\end{tabular}

Abbreviations: AMI, acute myocardial infarction; CAD, coronary artery disease; $\mathrm{CHF}$, congestive heart failure; LACS, lacunar stroke; mRS, modified Rankin Scale; NIHSS, National Institutes of Health Stroke Scale; PACS, partial anterior circulation; POCS, posterior circulation; TACS, total anterior circulation; TOAST, Trial of Org 10172 in Acute Stroke Treatment.

*values in median.

muscles play an important role during inspiration, contributing directly to the action of the diaphragm for the maintenance of abdominal wall tonus. The increase in abdominal pressure developed during inspiration is transmitted to the lower rib cage by the apposing diaphragmatic fibers and may, therefore, improve the ability of the diaphragm to raise the lower rib cage. The weakness of the abdominal muscles may affect the synergism between the abdominal and diaphragm muscles, impairing the capacity of the diaphragm to generate force..$^{23}$
Table 2. Hemodynamic variables of the patients

\begin{tabular}{lc}
\hline \multicolumn{1}{c}{ Variable } \\
\hline Respiratory rate $(\mathrm{bpm})$ & $19(12-36)$ \\
Blood pressure & \\
Systolic $(\mathrm{mmHg})$ & $144.5(96-191)$ \\
Diastolic $(\mathrm{mmHg})$ & $83(65-114)$ \\
Mean blood pressure $(\mathrm{mmHg})$ & $109.5(65-141)$ \\
Heart rate $(\mathrm{bpm})$ & $72.5(44-98)$ \\
Peripheral Oxygen Saturation $(\%)$ & $96(86-100)$ \\
Temperature $\left({ }^{\circ} \mathrm{C}\right)$ & $36.4(36.2-36.8)$ \\
\hline
\end{tabular}

In the present study, there was a negative correlation between inspiratory muscle strength and both age and BMI: older patients and those with higher BMI had lower inspiratory muscle strength.

In relation to age, this may be related to the aging process that brings about changes in muscle functionality and loss of muscle fibers; this also occurs in the respiratory system. One of the main changes in the respiratory system with advancing age is reduction of the elastic recoil of the lungs and the compliance of the chest wall, leading to progressive stiffening due to the process of calcification of the ribs and vertebral joints..$^{24,25}$

Watsford et al conducted a study with 72 elderly people divided into 2 groups of men and women and subdivided by age group (group A: 50-59, group B: 60-69, and group C: $70-79$ years). ${ }^{26}$ There was a difference in the rate of muscle strength reduction between men and women, but a reduction in RMS was observed in both sexes, and the higher the age group the greater the reduction in RMS. In a similar study with 100 men and women aged 4089 years, divided into 5 subgroups by age group, there was a decrease in RMS with age. ${ }^{27}$

The mechanical effects of obesity on the respiratory system are well established. Obese subjects commonly have lower RMS, because the abdominal pressure influences the curvature and movement of the dia-

Table 3. Comparison of the mean of the values obtained and predicted (in $\mathrm{CmH}_{2} \mathrm{O}$ ), of the respiratory pressures

\begin{tabular}{ccrcl}
\hline \multirow{2}{*}{ Sex } & Pressure & Obtained & Predicted & $P^{*}$ \\
\hline \multirow{2}{*}{ Man } & MIP & $85 \pm 36.2$ & $109.7 \pm 7.7$ & .05 \\
& MEP & $82.4 \pm 28.9$ & $119.13 \pm 7.8$ & .001 \\
\multirow{4}{*}{ Woman } & MIP & $46.9 \pm 25.4$ & $78.2 \pm 7.4$ & .001 \\
& MEP & $51.2 \pm 28.8$ & $75.5 \pm 9.2$ & .001 \\
Total & MIP & $62.4 \pm 35.3$ & $89.4 \pm 16.8$ & .001 \\
& MEP & $65.2 \pm 35.9$ & $91.1 \pm 22.6$ & .001 \\
\hline
\end{tabular}

Abbreviations: MEP, maximal expiratory pressure; MIP, maximal inspiratory pressure.

$*$ Student's $t$-test; MIP predicted: $\operatorname{man}=-.80$ (idade) +155.3 ; woman $=-.49$ (idade) +110.4 . MEP predicted: $\operatorname{man}=-.81$ (idade) $+165.3 ;$ woman $=-.61$ (idade $)+115.6$. 
Table 4. MIP according to the admission clinical condition, corrected for the effect of age and BMI

\begin{tabular}{|c|c|c|c|c|c|}
\hline Variables & $\beta$ & SE & $P$ & \multicolumn{2}{|c|}{ CI $95 \%$} \\
\hline Age & .51 & .41 & .227 & -.36 & 1.39 \\
\hline BMI & -4.39 & 1.09 & .001 & -6.71 & -2.07 \\
\hline Hypertension & 9.29 & 20.02 & .649 & -33.38 & 51.95 \\
\hline Smoking & -15.36 & 11.23 & .192 & -39.29 & 8.58 \\
\hline Obesity & 24.80 & 19.16 & .215 & -16.05 & 65.64 \\
\hline Diabetes & -.99 & 15.01 & .948 & -32.99 & 31.02 \\
\hline Alcoholism & -27.22 & 13.52 & .062 & -56.05 & 1.60 \\
\hline Dyslipidemia & 7.75 & 12.52 & .545 & -18.93 & 34.43 \\
\hline Prior stroke & -.17 & 13.54 & .990 & -29.03 & 28.69 \\
\hline Prior mRS & 2.02 & 8.87 & .823 & -16.89 & 20.92 \\
\hline NIHSS at admission & 3.02 & 2.20 & .190 & -1.67 & 7.71 \\
\hline
\end{tabular}

Abbreviations: $\beta$, beta estimate; BMI, body mass index; CI, confidence interval; MIP, maximal inspiratory pressure; mRS, modified Rankin scale; NIHSS, National Institutes of Health Stroke Scale; SE, standard error.

$\mathrm{pSW}=0.565 \mathrm{R}^{2}=88 \%$.

phragm, changing the generation of inspiratory pressure. ${ }^{28,29}$ Some authors suggest that RMS in obesity may be compromised by the increased load that the muscles are required to overcome, and by some reduction in their capacity. ${ }^{30,31}$ Chlif et al demonstrated that MIP was considerably lower in obese patients when compared with the control group. ${ }^{32}$ Excessive adipose tissue around the chest wall may alter normal lung function, reducing both the expiratory reserve volume and functional residual capacity, due to changes in the mechanics of the thoracic wall. ${ }^{33}$

In a systematic review with an aim to examine the effects of respiratory muscle training on respiratory function, RMS, and exercise tolerance in patients poststroke, the authors concluded that respiratory muscle training should be considered an effective method of improving respiratory function, inspiratory muscle strength, and exercise tolerance in patients poststroke. ${ }^{34}$ The evaluation and training of RMS has become increasingly important in stroke units, being an important parameter for functional recovery and for a decrease in the number of complications during hospitalization.

The main limitations of our study were the sample size, heterogeneity of the topographies of the stroke, and that half of the patients underwent physical therapy through an internal management process. The level of physical activity and sedentary behavior of the study participants were not evaluated, and this factor may be associated with a reduction in the overall muscular strength of the individuals. However, this work makes an important contribution to international stroke research in showing that obese and older individuals tend to suffer decreased RMS and are more susceptible to complications in the acute phase of stroke; multiprofessional teams should constantly monitor these cases. Based on the results obtained, there is a reduction of RMS in the acute phase of stroke, and RMS was lower in individuals with increased age and BMI.

Table 5. MEP according to admission clinical condition, corrected for BMI effect

\begin{tabular}{|c|c|c|c|c|c|}
\hline Variable & $\beta$ & SE & $P$ & \multicolumn{2}{|c|}{ CI $95 \%$} \\
\hline BMI & 3.89 & .62 & .000 & 2.57 & 5.21 \\
\hline Hypertension & -14.45 & 23.32 & .544 & -63.88 & 34.99 \\
\hline Smoking & 24.08 & 13.36 & .090 & -4.24 & 52.40 \\
\hline Obesity & -33.92 & 19.70 & .104 & -75.67 & 7.84 \\
\hline Diabetes & -11.69 & 16.18 & .480 & -46.00 & 22.61 \\
\hline Alcoholism & 26.81 & 14.50 & .083 & -3.93 & 57.56 \\
\hline Dyslipidemia & -26.77 & 14.49 & .083 & -57.48 & 3.95 \\
\hline Prior stroke & 13.29 & 15.95 & .417 & -20.53 & 47.11 \\
\hline Prior mRS & -16.75 & 9.32 & .091 & -36.52 & 3.01 \\
\hline NIHSS at admission & -4.58 & 2.50 & .086 & -9.89 & .73 \\
\hline
\end{tabular}

Abbreviations: $\beta$, beta estimate; BMI, body mass index; CI, confidence interval; MEP, maximal expiratory pressure; mRS, modified Rankin scale; NIHSS, National Institutes of Health Stroke Scale; SE, standard error.

$\mathrm{pSW}=0.974 \mathrm{R}^{2}=85 \%$. 
Acknowledgments: The investigators would like to acknowledge the Clinical Hospital at Botucatu Medical School for supporting this study.

\section{References}

1. Feigin VL, Forouzanfar MH, Krishnamurthi R, et al. Global and regional burden of stroke during 1990-2010: findings from the Global Burden of Disease Study 2010. Lancet 2014;383:245-254.

2. Falcão IV, Carvalho EMF, Barreto KML, et al. Acidente vascular precoce: implicações para adultos em idade produtiva atendida pelo sistema único de saúde. Rev Bras Saúde Matern Infant 2004;4:95-102.

3. Saposnik G, Del Brutto OH. for the Iberoamerican Society of Cerebrovascular Diseases. Stroke in South America: a systematic review of incidence, prevalence, and stroke subtypes. Stroke 2003;34:2103-2108.

4. Mansur AP, de Souza MFM, Favarato D, et al. Stroke and ischemic heart disease mortality trends in Brazil from 1979 to 1996. Neuroepidemiology 2003;22:179-183.

5. Caplan LR, Easton JD, Fayad PB, et al. Transient ischemic attack-proposal for a new definition. N Engl J Med 2002;347:1713-1716.

6. Saver JL. Proposal for a universal definition of cerebral infarction. Stroke 2008;39:3110-3115.

7. Patel A, Duncan P, Lai S, et al. The relation between impairments and functional outcomes poststroke. Arch Phys Med Rehabil 2000;81:1357-1363.

8. Jorgensen $H$, Nakayama $H$, Raaschou $H$, et al. Outcome and time course of recovery in stroke, part I: time course. Arch Phys Med Rehabil 1995;76:406-412.

9. Widdicombe JG, Addington WR, Fontana GA, et al. Voluntary and reflex cough and the expiration reflex; implications for aspiration after stroke. Pulm Pharmacol Ther 2011;24:312-317, 41.

10. Matz K, Seyfang L, Dachenhausen A, et al. for the Austrian Stroke Unit Registry Collaborators. Post-stroke pneumonia at the stroke unit-a registry based analysis of contributing and protective factors. BMC Neurol 2016;16:107.

11. Zhou Z, Vincent F, Salle J, et al. Acute stroke phase voluntary cough and correlation with maximum phonation time. Am J Phys Med Rehabil 2012;91:494-500, 42.

12. Yoon J, Park J, Lee D, et al. Comparisons of respiratory function and activities of daily living between spinal cord injury and stroke patients and normal elderly people. J Phys Ther Sci 2011;24:465-469, 43.

13. Harraf F, Ward K, Man W, et al. Transcranial magnetic stimulation study of expiratory muscle weakness in acute ischemic stroke. Neurology 2008;71:2000-2007, 44.

14. Ward K, Seymour J, Steier J, et al. Acute ischaemic hemispheric stroke is associated with impairment of reflex in addition to voluntary cough. Eur Respir J 2010;36:13831390.

15. Syabbalo N. Assessment of respiratory muscle function and strength. Postgrad Med J 1998;74:208-215.

16. Polkey MI, Green M, Moxham J. Measurement of respiratory muscle strength. Thorax 1995;50:1131-1135.

17. Cincura C, Pontes-Neto OM, Neville IS, et al. Validation of the National Institutes of Health Stroke Scale, modified
Rankin scale and Barthel index in Brazil: the role of cultural adaptation and structured interviewing. Cerebrovasc Dis 2009;27:119-122.

18. Neder JA, Andreoni S, Lerario MC, et al. Reference values for lung function tests. II. Maximal respiratory pressures and voluntary ventilation. Braz J Med Biol Res 1999;32:719-727.

19. O'Donnell MJ, Chin SL, Rangarajan S, et al. Global and regional effects of potentially modifiable risk factors associated with acute stroke in 32 countries (INTERSTROKE): a case-control study. Lancet 2016;388:761-775.

20. Martins SCO, Brondani R, Friedrich M, et al. Quatro anos de experiência no tratamento trombolítico do AVC isquêmico na cidade de Porto Alegre. Revista Neurociencias 2006;14:31-36.

21. Silverman IE, Beland DK, Bohannon RW, et al. Expanding the range of therapies for acute ischemic stroke: the early experience of the Regional Stroke Center at Hartford Hospital. Conn Med 2004;68:419-429.

22. Salmela LT, Parreira VF, Britto RR, et al. Respiratory pressures and thoracoabdominal motion in community dwelling chronic stroke survivors. Arch Phys Med Rehabil 2005;86:1974-1978.

23. Ewig JM, Griscom NT, Wohl ME. The effect of the absence of abdominal muscles on pulmonary function and exercise. Am J Respir Crit Care Med 1996;153:13141321.

24. Kim J, Sapienza CM. Implications of expiratory muscle strength training for rehabilitation of the elderly: tutorial. J Rehabil Res Dev 2005;42:211-224.

25. Polkey MI, Lyall RA, Mocham J, et al. Respiratory aspects of neurological disease. J Neurol Neurosurg Psychiatry 1999;66:5-15.

26. Watsford M, Murphy AJ, Pine MJ. The effects of ageing on respiratory muscle function and performance in older adults. J Sci Med Sport 2007;10:36-44.

27. Simões RP, Auad MA, Dionísio J, et al. Influência da idade e do sexo na força muscular respiratória. Fisioter Pesqui 2007;14:36-41.

28. Sahebjami H, Gartside PS. Pulmonary function in obese subjects with a normal FEV1/FVC ratio. Chest 1996;110:1425-1429.

29. Naimark A, Cherniack RM. Compliance of the respiratory system and its components in health and obesity. J Appl Physiol 1960;15:377-382.

30. Babb TG, Korzick D, Meador M, et al. Ventilatory response of moderately obese women to submaximal exercise. Int J Obes 1991;15:59-65.

31. Dempsey JA, Reddan W, Balke B, et al. Work capacity determinants and physiologic cost of weight-supported work in obesity. J Appl Physiol 1966;21:1815-1820.

32. Chlif M, Keochkerian D, Feki Y, et al. Inspiratory muscle activity during incremental exercise in obese men. Int J Obes 2007;31:1456-1463.

33. Chlif M, Keochkeriana D, Choquet D, et al. Effects of obesity on breathing pattern, ventilatory neural drive and mechanics. Respir Physiol Neurobiol 2009;168:198-202.

34. Gomes-Neto M, Saquetto MB, Silva CM, et al. Effects of respiratory muscle training on respiratory function, respiratory muscle strength, and exercise tolerance in patients poststroke: a systematic review with metaanalysis. Arch Phys Med Rehabil 2016;97:1994-2001. 